\title{
Uma Implementação da Aprendizagem Baseada em Problemas (PBL) na Pós-Graduação em Engenharia sob a Ótica dos Alunos
}

\section{An Implementation of Problem-Based Learning (PBL) in Postgraduate Engineering Education According to the Students}

\author{
Luis Roberto de Camargo Ribeiroㅜㄹ Maria da Graça Nicoletti Mizukami²
}

Resumo

\begin{abstract}
A Aprendizagem Baseada em Problemas ou PBL (Problem-Based Learning), ao contrário do modelo convencional, usa o problema para motivar, focar e iniciar a aprendizagem. Além de promover a construção dos conhecimentos a PBL objetiva o desenvolvimento de habilidades e atitudes tidas como importantes para uma prática profissional efetiva. Este trabalho, uma pesquisa-intervenção de natureza qualitativa, analisa a avaliação de alunos sobre uma implementação da PBL em uma disciplina de pós-graduação em engenharia de uma universidade pública em São Carlos, SP. Os dados utilizados neste trabalho foram coletados por meio de observação participante, entrevistas não estruturadas e de um questionário de final de curso respondido pelos alunos, no qual lhes foi pedido que avaliassem esta abordagem de ensino, suas vantagens e desvantagens e o alcance de seus objetivos educacionais, ou seja, conhecimentos, habilidades e atitudes. Os resultados mostram que, apesar de aumentar seu tempo de estudo e carga de trabalho, a maioria dos alunos avalia positivamente a metodologia por propiciar aulas dinâmicas e motivadoras e por promover habilidades interpessoais, de pesquisa e solução de problemas etc. e atitudes tais como respeito aos pontos de vista de colegas, adaptabilidade, autonomia, colaboração, etc.
\end{abstract}

Palavras-chave: PBL. Aprendizagem baseada em problemas. Ensino superior. Ensino de pós-graduação.

\begin{abstract}
Problem-based Learning (PBL) is an instructional method that - contrary to conventional models that place application problems after the introduction of a concept or content - uses a problem to motivate, focus and initiate learning. Besides promoting the construction of knowledge, this methodology aims at the development of skills and attitudes deemed as important for effective professional practice. This research, of a qualitative nature, analyses a PBL implementation developed in a course of the postgraduate engineering curriculum at a public university in Brazil. The data were collected through participant observation, non-structured interviews and an end-of-semester questionnaire, when the students were asked to evaluate the methodology, its advantages and disadvantages and its attainment to the course educational goals, i.e., knowledge, skills and attitudes. Despite increasing their study time and workload, most of the students favored the methodology for providing more motivating and active classes, and for assisting in the development of interpersonal, research and problem-solving skills as well as attitudes such as respect for other points of view, adaptability, self-directed learning, collaboration etc.
\end{abstract}

Key words: PBL. Problem-based learning. Tertiary education. Post-graduate education.

\footnotetext{
B.Sc Eng., M.Sc. Eng., Doutorando, Programa de Pós-Graduação em Educação, UFSCar, São Carlos, SP, Fone/Fax: 260-8356, Email: luisrcr@iris.ufscar.br.

2 Ph.D., Professora, Departamento de Metodologia de Ensino, UFSCar, São Carlos, SP, Fone/Fax: 260-8356, Email: dmgn@power.ufscar.br.
} 


\section{Introdução}

Vivemos em um mundo em processo constante de mudanças, alimentado por grandes avanços tecnológicos, ao qual a educação não poderia estar imune. Uma área particularmente afetada por essas transformações é o ensino de engenharia, pelo fato de abrigar grande parte do conhecimento com aplicação imediata. Seus efeitos mais visíveis são o aumento do volume de conhecimentos e sua rápida obsolescência, o que obriga os engenheiros a continuamente reaprenderem sua profissão.

O ensino de engenharia também é afetado por aspectos inerentes ao campo de atividade do engenheiro, que se expandiu muito desde sua origem para abrigar diversas áreas das organizações produtivas, isto é, pesquisa e desenvolvimento, finanças, marketing, produção, serviços ao consumidor etc. A essa expansão se soma a instabilidade do mercado de trabalho do engenheiro, que pode fazer com que um engenheiro, durante sua vida, assuma posições diferentes dentro das empresas, trabalhe em diferentes empresas e setores produtivos ou mesmo abra seu próprio negócio.

Esta conjunção de fatores acaba por demandar deste profissional outros atributos além de conhecimentos técnicos sólidos. Para definir esses atributos, muitas universidades e escolas de engenharia recorrem a pesquisas voltadas ao levantamento de perfis profissionais desejáveis, principalmente junto a empregadores, especialistas e engenheiros que atuam na área. Alguns dos atributos mais citados nessas pesquisas são: (a) conhecimentos: domínio dos princípios fundamentais da engenharia (ciência e tecnologia), conhecimentos em áreas tais como computação, administração de empresas, lucros, impacto da tecnologia no meio ambiente e nas pessoas etc.; (b) habilidades: comunicação e relacionamento interpessoal, desenvolvimento de projetos, análise de problemas, síntese de soluções referenciadas a práticas em uso, orientação para o trabalho em equipes como líder e liderado, gestão de recursos etc.; e (c) atitudes: ética, integridade e responsabilidade para com a sociedade e para com a profissão, preocupação com o meio ambiente, iniciativa, capacidade empreendedora, criatividade, capacidade de adaptação a mudanças constantes, disposição de procurar especialistas quando necessário, motivação e interesse para o aprendizado contínuo durante suas carreiras etc.

Embora se reconheça a importância do desenvolvimento desses atributos - haja vista que no Brasil muitos deles estão contemplados nas diretrizes curriculares para cursos de engenharia (BRASIL, 2002) - a questão que se coloca às escolas e departamentos de engenharia, e universidades de modo geral, é: como incorporar um corpo crescente de conhecimentos e como desenvolver habilidades e atitudes necessários à boa atuação profissional sem sobrecarregar os currículos ou estender os cursos?

A resposta pode estar em alguns autores, tais como Zabala (1998), que acreditam ser possível trabalhar estas três categorias, isto é, conhecimentos, habilidades e atitudes, simultaneamente em sala de aula. Uma das formas de conseguir isto seria através da utilização de metodologias de ensino tais como a PBL, já que esta abordagem educacional é reconhecida, segundo Savin-Baden (2000), por oferecer aos alunos um meio de adquirir conhecimentos e desenvolver as habilidades e atitudes valorizadas na vida profissional sem a necessidade de disciplinas ou cursos especialmente concebidos para este fim.

\section{AAprendizagem Baseada em Problemas (PBL)}

A PBL, em seu nível mais fundamental, é um método caracterizado pelo uso de problemas do mundo real para encorajar os alunos a desenvolverem o pensamento crítico e habilidades de solução de problemas e a adquirirem conhecimento sobre os conceitos essenciais da área em questão. A PBL originou-se, como proposta metodológica, em 1969 na McMaster University, Canadá, para o estudo de medicina, mas é possível encontrar exemplos de implementação da PBL em todo o sistema educacional: tanto em universidades (WILKERSON; 
GIJSELAERS, 1996) quanto em escolas de ensino fundamental e médio (FOGARTY, 1998). No ensino superior, tem sido bem sucedida em áreas diversas, tais como no ensino de arquitetura (KINGSLAND, 1996), administração de empresas (STINSON; MILTER, 1996), engenharia (WOODS, 1996) etc.

Apesar de ter sido sistematizada há pouco mais de trinta anos, a PBL não é uma abordagem nova. Muitos de seus elementos norteadores já foram contemplados por educadores e pesquisadores educacionais do mundo todo. No entanto, a PBL pode ser considerada inovadora na medida em que consegue incorporar e integrar conceitos de varias teorias educacionais e operacionalizá-los na forma de um conjunto consistente de atividades. Por exemplo, algumas atividades envolvidas nesta metodologia, tais como a identificação, a investigação e a solução de problemas, o trabalho em equipe etc., são indicadas pela teoria da psicologia cognitiva como formas de aprimoramento dos processos de ensinoaprendizagem (GIJSELAERS, 1996).

Nesta perspectiva, muitas atividades educacionais poderiam ser consideradas PBL, tais como projetos e pesquisas, porém para Woods (2000) da McMaster University, no ambiente de aprendizagem PBL a aprendizagem deve ser direcionada por um problema. Ou seja, um problema de fim aberto, que não comporta uma solução correta única, deve preceder à teoria, atuando como o foco da aprendizagem, e promover a integração dos conceitos e habilidades necessários para sua solução (BARROWS, 2001). Esta é a principal característica que distingue a PBL de outros processos de ensino-aprendizagem.

\section{O processo PBL}

Originalmente, a PBL é implementada em todo o curso e orienta por um conjunto de problemas que formam a espinha dorsal de seu currículo. Porém, existem relatos de aplicação bem sucedida da PBL como uma estratégia educacional parcial, isto é, em disciplinas isoladas dentro de um currículo convencional (WILKERSON; GIJSELAERS, 1996) ou mesmo em partes de disciplinas (STEPIEN; GALLAGHER, 1998).

As diferentes implementações da PBL têm em comum um processo que pode ser resumido no seguinte conjunto de atividades (DUCH, 2000; BARROWS, 2001): (1) apresenta-se um problema aos alunos que, em grupos organizam suas idéias, tentam defini-lo e solucioná-lo com o conhecimento que já possuem; (2) por meio de discussão, os alunos levantam e anotam questões de aprendizagem (learning issues) acerca dos aspectos do problema que não compreendem; (3) os alunos priorizam as questões de aprendizagem levantadas e planejam quando, como, onde e por quem estas questões serão investigadas para serem posteriormente partilhadas com o grupo; (4) quando os alunos se reencontram, exploram as questões de aprendizagem anteriores, integrando seus novos conhecimentos ao contexto do problema; e (5) depois de terminado o trabalho com o problema, os alunos avaliam o processo, a si mesmos e seus pares de modo a desenvolverem habilidades de auto-avaliação e avaliação construtiva de colegas, imprescindíveis para uma aprendizagem autônoma eficaz.

\section{O papel do professor e dos alunos na PBL}

Este conjunto de atividades não só acarreta mudanças no processo de ensino-aprendizagem como também coloca desafios para seus principais atores: alunos e docentes. A PBL implica diferentes papéis para estes atores, quando comparados àqueles associados ao ensino convencional, já que a aprendizagem ocorre em um ambiente de apoio e colaboração. Segundo Barrows (2001), o papel dos docentes aproxima-se do facilitador, orientador, coaprendiz, mentor ou consultor profissional. Nesta metodologia, os docentes concebem cursos baseados em problemas do mundo real, com fraca estruturação, delegam responsabilidade aos alunos e selecionam conceitos que facilitarão a transferência de conhecimentos pelos alunos, desencorajam a resposta correta única, ajudando os alunos a 
delinearem questões, formularem problemas, explorarem alternativas e tomarem decisões eficazes. Em contrapartida, os alunos responsabilizam-se pela aprendizagem: trabalham em grupos para identificar, analisar e resolver problemas utilizando conhecimentos de cursos e experiências anteriores, ao invés de simplesmente relembrá-los; avaliam suas próprias contribuições, além das de outros membros e do grupo como um todo e interagem com o corpo docente de modo a fornecer feedback imediato acerca do desempenho do curso com a finalidade de melhorá-lo continuamente.

\section{Objetivos educacionais na PBL}

É importante ressaltar que, nesta abordagem apesar de técnicas de solução de problemas serem fundamentais, a PBL não se resume nelas. Nesta metodologia, o conhecimento construído na busca da solução dos problemas e as habilidades e atitudes desenvolvidas neste processo são mais relevantes que a solução per si. Barrows (1996) identifica alguns objetivos educacionais da PBL para o ensino de medicina aplicáveis ao ensino de outras áreas de conhecimento: (a) a aquisição de uma base de conhecimento integrada; (b) a aquisição de uma base de conhecimento estruturada ao redor de problemas reais encontrados no campo de atuação do profissional em questão; (c) a aquisição de uma base de conhecimento vinculada a processos de solução destes problemas e o desenvolvimento de um processo eficaz e eficiente de solução de problemas; e (d) o desenvolvimento de habilidades de aprendizagem autônoma eficaz e de habilidades de trabalho em grupo.

Apesar de estarem direcionados para o ensino de graduação, esses objetivos parecem ser igualmente válidos para programas de mestrado e doutorado - objeto de estudo deste trabalho - já que é possível imaginar que a PBL concorra para o cumprimento de dois objetivos de cursos de pósgraduação presentes na Lei 5.540: a formação de pesquisadores e docentes para o ensino superior.
Considerando a formação de pesquisadores, o uso de metodologias como a PBL só teria a acrescer, posto que seu processo se assemelha muito ao método científico. Suas fases de definição e análise do problema, levantamento de hipóteses, busca de fundamentação teórica e aplicação desta na sua solução, troca de informações, apresentação de resultados, síntese dos conhecimentos adquiridos etc. podem contribuir tanto para o domínio dos conceitos da área de conhecimento do pesquisador, quanto para o aprimoramento de habilidades necessárias à sua atuação como tal, uma vez que a pesquisa científica envolve muitas atividades que requerem habilidades comunicativas e interpessoais (KAUFMAN; MANN, 2001).

Quanto à formação de docentes para o ensino superior, é possível imaginar que a experiência com uma metodologia como a PBL poderia ajudar a sensibilizar os alunos para a existência de alternativas pedagógicas às aulas que provavelmente tiveram, pautadas em um modelo de transmissão de conhecimentos, centrado no professor. Além disso, o fato de a PBL contemplar mecanismos de autoavaliação, avaliação de pares e do processo educacional também pode ajudar a promover nos alunos uma atitude reflexiva acerca do aprender e do ensinar, e isso poderá ser-lhes útil, no que tange ao desenvolvimento dos conhecimentos necessários a uma atividade docente eficaz. Isto pode ser especialmente valioso em cursos de pós-graduação, como acontece na área das engenharias, nos quais a maioria dos alunos advém de bacharelados sem nenhum conteúdo ou prática pedagógica e, apesar disso eles, raramente têm a possibilidade de obtê-los neste momento de sua formação. Enfim, a vivência em uma metodologia não convencional como a PBL poderia estimular estes alunos a fazerem uma reflexão sobre suas práticas em sua futura carreira acadêmica e a não repetirem, como observa Cunha (1996), os mesmos rituais pedagógicos que viveram.

Com relação a um terceiro objetivo da pósgraduação, isto é, propiciar a especialização ou atualização dos conhecimentos de alunos que 
utilizarão esta formação para outros fins, a aplicação dessa metodologia e seus ganhos eqüivaleriam àqueles colocados anteriormente para profissionais que atuarão em empresas ou em outras organizações. Em suma, uma das características que tornam a PBL interessante para instituições de ensino superior, na graduação ou pós-graduação, é a possibilidade de se atingir objetivos educacionais mais amplos, ou seja, não só a construção de conhecimentos por parte dos alunos, mas o desenvolvimento de habilidades e atitudes que lhes serão úteis em sua vida profissional futura, independentemente do caminho profissional escolhido.

\section{Objetivos do Trabalho}

Este trabalho faz parte de um estudo sobre a viabilidade de implementação da metodologia de ensino PBL em disciplinas de um curso de engenharia. Neste momento, a investigação enfoca como os alunos de um curso de pós-graduação avaliam esta abordagem de ensino, suas vantagens e desvantagens e o alcance de seus objetivos educacionais, ou seja, conhecimentos, habilidades e atitudes.

\section{Metodologia}

Esta pesquisa pode ser considerada uma pesquisaintervenção, já que é de natureza qualitativa na medida em que busca investigar algo em seu contexto natural, tentando compreender, ou interpretar, os fenômenos em termos dos significados que as pessoas lhes conferem (DENZIN; LINCOLN, 1994). Este trabalho também adota uma perspectiva colaborativa (COLE; KNOWLES, 1993), ou seja, contemplou um trabalho conjunto dos pesquisadores e do professor durante as fases de planejamento e implementação da metodologia e, de certa forma, na coleta e análise dos dados.

Para responder à questão de pesquisa, a metodologia PBL foi desenvolvida com uma turma de pós-graduandos de um departamento de engenharia de produção de uma universidade pública de São Carlos, SP, no primeiro semestre de 2002. A turma era composta de 23 alunos (17 homens e 6 mulheres) de mestrado ou doutorado, com idades de 24 a 55 anos. As fontes de coleta de dados utilizadas foram entrevistas, observação participante e questionários. Os dados apresentados neste trabalho derivam principalmente das observações em sala de aula e de um questionário de final de semestre (respondidos por 21 alunos). Neste questionário foi pedido aos alunos que, individualmente, avaliassem a metodologia, sua eficácia quanto ao atendimento aos objetivos da disciplina (conhecimentos, habilidades e atitudes), suas vantagens e desvantagens e dessem sugestões de melhoria. Além disso, pediu-se-lhes que opinassem sobre a dinâmica da aula nesta abordagem, tais como as formas de apresentação, procedimento de avaliação e trabalho em grupo.

\section{A intervenção}

A implementação da PBL - pautada no conjunto de atividades e nos princípios norteadores da PBL deu-se em uma disciplina sobre Teoria Geral da Administração (TGA) que compreendia um encontro semanal de 200 minutos durante 15 semanas. Nela foram apresentados 12 problemas (um por semana) enfocando diferentes tópicos da TGA. Na ementa apresentada aos alunos constavam, além dos objetivos gerais da disciplina (desenvolvimento da visão do todo e de competências relacionadas ao Pensamento Administrativo), objetivos quanto aos conhecimentos (os Movimentos do Pensamento Administrativo, o modelo de diagnóstico etc.), às habilidades (habilidades de comunicação oral e escrita, habilidades de solução de problemas, habilidades interpessoais etc.) e às atitudes (respeito aos outros e às opiniões de outros, ética, respeito a regras estabelecidas pelo grupo, cooperação etc.). Junto à ementa foi anexado um texto explicativo sobre a metodologia, seus princípios e procedimentos, os quais também foram discutidos no primeiro encontro.

Os alunos dividiram-se espontaneamente em grupos de 4 ou 5 , nos quais assumiram, alternando- 
se a cada problema, os papéis de líder, redator, portavoz e membros participantes. Na segunda metade da disciplina, estes grupos originais foram re-arranjados pelo professor, e passaram a ser chamados de equipes, de modo a encorajar relações mais impessoais entres os alunos, fomentar a troca de experiências com relação ao trabalho em grupo e promover sua eficácia. Um ciclo completo da metodologia consistia de várias fases e iniciava-se na segunda metade do encontro semanal com a apresentação do problema seguida da discussão em grupo. Nesta discussão, os alunos analisavam o problema, levantavam hipóteses acerca de suas possíveis causas, listavam os conceitos que poderiam ajudá-los a resolvê-lo e planejavam a estratégia de trabalho em grupo, ou seja, a pesquisa, a síntese dos conhecimentos pesquisados, aplicação na solução do problema e a apresentação dos resultados. No encontro seguinte cabia aos redatores entregar um relatório final com os resultados das pesquisas de seus grupos e, aos porta-vozes, apresentá-lo oralmente. Os resultados foram apresentados na forma de seminários, pôsteres e dramatizações (as duas últimas somente a partir da metade da disciplina) com a participação de todos os grupos. As apresentações dos grupos eram seguidas por um debate entre os alunos e o professor, isto é, um fechamento coletivo, e uma síntese deste sobre o tópico em questão. Finalizando o ciclo, os grupos avaliavam o problema e o processo educacional e os líderes avaliavam, separadamente, seu próprio trabalho e o dos demais membros de seu grupo, conferindo conceitos (Excelente, Bom, Regular e Insuficiente) e escrevendo comentários complementares.

\section{Resultados e Discussão}

Todos os alunos avaliaram positivamente a metodologia de ensino utilizada por ser "eficaz ao incitar o aluno a buscar por novos conhecimentos" (A05), na medida em que "forçou o aluno a procurar os conceitos, entendê-los e aplicá-los. Fez com que os alunos interagissem e discutissem mais, melhorando suas habilidades e o entendimento dos conceitos” (A11).

\section{Sobre as vantagens e desvantagens da abordagem utilizada}

As vantagens apontadas pelos alunos foram atribuídas principalmente ao fato de esta metodologia de ensino ser motivadora, tornar a aula dinâmica e estimular o desenvolvimento de habilidades interpessoais e de pesquisa, como colocam A19: “A aula torna-se mais dinâmica e assim é mais facilmente entendida; os alunos aprendem a buscar o conhecimento e [...] a trabalhar em grupo (o que é mais complicado e importante de ser treinado)" e A14: “A vantagem é de não ter o conhecimento pronto para ser digerido, mas ter que buscá-lo e a troca de conhecimentos foi muito satisfatória” Outras vantagens elencadas foram a possibilidade de "Aprender a [...] solucionar um problema na prática" (A20) e "A integração de conhecimentos e de diferentes visões que cada um passou a ter sobre o tema” (A02).

O maior envolvimento e participação do aluno, imprescindíveis em metodologias como a PBL, tiveram uma avaliação ambígua, como mostram A06: "É uma metodologia interessante, mas exige do aluno um maior comprometimento e responsabilidade. Isso é esperado de alunos de pós-graduação” e A13: “A desvantagem é que todos devem estar motivados para que a metodologia [se] desenvolva bem”. Este maior comprometimento exigido dos alunos também acarreta um aumento do tempo e da carga de trabalho, apontado como uma das desvantagens da metodologia e um dos pontos de insatisfação de alunos mais recorrentes na literatura sobre a PBL. Vários alunos levantaram esta questão neste estudo e alguns sugeriram algumas alternativas, tais como a distribuição dos encontros em dois dias da semana (A21) e a utilização de parte do tempo dos encontros em sala de aula para o trabalho em grupo (A14). Estas sugestões são confirmadas pelos estudos de Kingsland (1996), nos quais os alunos indicaram que se preocupavam mais com a distribuição das atividades e a disponibilização de espaços de trabalho apropriados do que com o aumento da carga de trabalho e tempo necessários às atividades per si. 
Outra desvantagem da metodologia seria a pressão por participação colocada sobre alunos mais introvertidos: "A disciplina da forma que foi dada força o aluno a participar e isso pode muitas vezes inibir o aluno devido às suas características” (A02). A este respeito, Kaufman e Mann (2001) colocam que, embora a PBL deva promover o aprimoramento das habilidades comunicativas e interpessoais dos alunos, isso deve ser feito de acordo com a personalidade e o nível de bem-estar de cada um. No caso de alunos mais introvertidos, estes autores sugerem, como acabou ocorrendo nesta implementação, que os requisitos não negociáveis da metodologia, tais como a participação, sejam explicitados aos alunos e que os benefícios advindos do desenvolvimento e do aprimoramento destas habilidades sejam ressaltados.

Outros alunos acreditam que o fato de o problema preceder à teoria pode ser uma desvantagem: "Para colegas que nunca tiveram contato com a Administração, tendo mais dificuldade no entendimento dos problemas propostos. Ficam mais inseguros” (A03). Este aspecto parece ser mais relevante na pósgraduação, na qual pode haver uma maior heterogeneidade de conhecimento sobre os assuntos tratados na disciplina. Porém, supõe-se que, pelo fato o problema motivar a busca da teoria, a PBL não requeira que se tenha uma base prévia de conhecimento. Tampouco demanda que todos os alunos tenham o mesmo nível de conhecimento sobre o assunto, já que está pautada na otimização da aprendizagem através da troca de informações entre os membros dos grupos, como sustenta Gijselaers (1996).

Mesmo o fato de a abordagem encorajar enfoques diferentes acerca de um mesmo tópico, uma característica positiva desta abordagem de ensino, foi visto de forma dúbia por alguns alunos, como sugere A15: “Talvez se a discussão em aula fosse mais direcionada para alguns pontos principais, o objetivo de conhecimento poderia ser melhor alcançado. Mas não sei se se perderia em outros lados, como por exemplo a principal vantagem dessa metodologia que é ver vários aspectos do mesmo problema. Não sei...”. É possível imaginar que o conflito de A15 e a preocupação de A03 a respeito da necessidade de conhecimentos prévios estejam refletindo suas vivências como alunos em ambientes de aprendizagem mais diretivas, com aquisição do conhecimento de forma lógica e seqüencial. É natural que a adoção de metodologias tais como a PBL cause conflitos, desestabilize algumas estratégias de aprendizagem e provoque reações por parte de alguns alunos, principalmente daqueles bem sucedidos em ambientes educacionais positivistas (STINSON; MILTER, 1996), mais centrados no professor.

\section{Sobre $o$ atendimento aos objetivos da disciplina (conhecimentos, habilidades e atitudes)}

Todos os alunos avaliaram que os objetivos gerais da disciplina foram alcançados. Um desses objetivos era contribuir para uma visão global sobre Teoria Administrativa e para o entendimento de que suas teorias não podem ser dissociadas do contexto histórico e social em que foram concebidas. Isto pode ser verificado na colocação de A19: "Foi importante pois conseguimos contextualizar historicamente os modelos de Administração utilizados” e de A07: "Foi possível identificar os grandes movimentos do pensamento administrativo, suas causas e conseqüências dentro do contexto sociocultural e econômico da evolução histórica da humanidade”.

Tomando os objetivos separadamente, a abordagem de ensino pode ter promovido a aquisição dos conhecimentos da forma descrita por Barrows (1996), ou seja, integrada, vinculada a processos de solução de problemas e estruturada ao redor de problemas relacionados à vida profissional dos alunos, tal como aparece nas falas de A02: "A disciplina proporcionou que os conhecimentos antes teóricos fossem aplicados em estudos de caso [problemas], o que proporcionou interessantes discussões sobre cada tema abordado" e de A10:

Quando fiz TGA na graduação não sabia que esta matéria serviria na minha vida profissional. Mas agora vejo a abrangência que este curso tem, permitindo 
ter uma visão geral de toda a organização e como podemos resolver diferentes problemas que existem dentro delas através de tudo que foi discutido no decorrer das aulas.

Porém, alguns alunos, como colocou A03 anteriormente, acreditam que esta abordagem de ensino pode não ser recomendável quando os alunos não tem uma base sobre o conhecimento em questão: "Os alunos sem base em Administração talvez não tenham conseguido construir adequadamente o prédio que abriga as teorias administrativas e suas derivações, por falta desta base” (A06). Esta suposição de A06 não encontra suporte na literatura, a qual indica que há apenas uma pequena diferença na aprendizagem de conhecimentos - sem considerar o desenvolvimento de habilidades e atitudes - a favor das metodologias convencionais (expositivas) (ALBANESE; MITCHELL, 1993; DOCHY et al., 2003). Mesmo pequena esta diferença é contestada por alguns autores, como Stinson e Milter (1996), por ser pautada em resultados de testes objetivos padronizados que medem apenas a capacidade dos alunos de recordarem conceitos descontextualizados e, também, por estes resultados demonstrarem mais uma fraqueza da implementação do que da PBL per si.

Com relação às habilidades, como indica A14: “A busca de conhecimento e a troca deles em grupos heterogêneos (muitos não eram da área administrativa) foi muito satisfatória”, aquelas promovidas pelo trabalho em grupo - sempre apontadas como desejáveis em pesquisas sobre o perfil de engenheiros e outros profissionais - são, de longe, as mais citadas pelos alunos como um dos grandes ganhos da metodologia. Além dessas habilidades, alguns alunos, tais como A12, relatam que "habilidades para a pesquisa, condensar, resumir e apresentar os problemas também foram alcançadas”. A capacidade da metodologia de promover o desenvolvimento de habilidades é um fato reconhecido pela literatura. Por exemplo, a metaanálise sobre os efeitos da PBL de Dochy et al. (2003, p.549) sugere "um efeito positivo robusto da PBL nas habilidades dos alunos".
Com relação às atitudes, alguns alunos sustentam que algumas atitudes, tais como o respeito a opinião de outros, adaptabilidade, autonomia, colaboração etc., podem ter sido encorajadas pela abordagem de ensino, como ilustram os seguintes trechos: "O modo de colocar e defender pontos de vista” (A14), "Atitudes diferentes de acordo com a situação e aprender a aprender, além de adquirir [...] ponto de vista crítico em relação aos temas abordados” (A04), "Colaboração, planejamento do tempo, cumprimento de prazos e de respeito às dificuldades dos colegas" (A12). Entretanto, a fala de alguns alunos evidencia que algumas atitudes, tais como ética e não corporativismo, podem não ter sido sempre exercitadas:

Eu fui sincera e considerei a equipe como uma organização (pelo menos nesta etapa). Porém muitos estavam preocupados com a nota, até 'combinando' de dar conceito E para todos, independente do seu desempenho no processo (da semana). Eu errei quando dei um conceito E para mim em um trabalho do grupo anterior, pois na realidade não consegui 'influenciar', como gostaria, o produto final (relatório) (A15).

Atitudes como as denunciadas por A15 têm raízes sociais e culturais profundas e são, portanto, difíceis de serem desestabilizadas. Não se esperava que uma disciplina, em apenas um semestre, fosse capaz de modificar estratégias e práticas forjadas em muitos anos de uma escolarização cujo objetivo primeiro é obter notas para ser aprovado. Este limite também foi percebido por A21 que, apesar de verificar algumas mudanças com respeito a algumas atitudes, foi perspicaz quanto ao seu escopo:

No caso de atitudes acho que a mudança de postura em classe, de algumas pessoas, foi observada (mudança no sentido de compreender outras abordagens do mesmo problema, vinda de outros elementos do grupo de trabalho, e ser mais flexível em relação a elas). No caso de atitudes no sentido de mudança de postura pessoal, fora da classe, é um processo muito pessoal, lento.

De qualquer forma, a abordagem de ensino parece ter exigido de alguns alunos atitudes tais como a 
responsabilidade pela própria aprendizagem, ou seja, "a consciência de que a responsabilidade para atingir estes objetivos [da disciplina] é do aluno” (A15), e uma "maior flexibilidade, principalmente o saber ouvir e no relacionamento com o grupo, procurando compreender porque havia tanta distinção de pensamento, de maneiras de agir e interpretar as organizações e seus problemas” (A03).

\section{Sobre alguns aspectos da aula nesta abordagem}

A metodologia, na forma como foi implementada, consistia de várias fases que ia desde a apresentação do problema pelo professor até o fechamento coletivo. Quando instados a opinar sobre estas fases, alguns alunos preferiram fazê-lo de forma global, como mostram A16: "Sem muitos comentários sobre as partes da aula, visto a grande discussão gerada sobre esta metodologia, boa e interessante” e A17:

Não encontrei muitos problemas em relação à metodologia, acho que as fases de planejamento, pesquisa e fechamento no grupo contribuíram muito, pois simulam o andamento do processo de solução de problemas em várias organizações. A apresentação é ótima, haja vista que nos obriga a trabalhar a comunicação, a expressão e as técnicas de apresentação.

Um dos aspectos mais valorizados pelos alunos nesta abordagem, mencionado anteriormente, foram os momentos de trabalho em grupo na sala de aula e fora dela. A fase de planejamento foi considerada fundamental porque dava uma direção ao trabalho do grupo e promovia o "entendimento do problema, definia tudo o que deveria ser buscado/estudado, além dos prazos, tarefas a serem feitas" (A11). No entanto, uma estratégia de trabalho planejada por alguns grupos, ou seja, a divisão de tarefas e posterior troca de informações e síntese nos grupos, nem sempre contava com o aval de todos os alunos. A06 opinou que "todos deviam pesquisar tudo e não esfacelar o problema e cada um cuidar de uma parte".

A maioria dos alunos salientou o fato de o trabalho em grupo, em outras fases, ter agido como um catalisador de discussões: ("Estimula a participação de todos através de uma discussão saudável em que se somam visões e percepções diferenciadas”(A06)), ocorreram algumas dificuldades, por vezes atribuídas a um planejamento deficiente do próprio grupo: “Às vezes ocorreram alguns problemas [na fase de fechamento do problema no grupo], o que precisou ser mais especificado no planejamento" (A19). Contudo, parece que os fatores tempo e distância já que muitos dos alunos residiam fora de São Carlos - foram os principais responsáveis por estas dificuldades, o que acabou levando ao desenvolvimento de estratégias interessantes, como conta A18: "Para grupos com integrantes de lugares distantes as salas virtuais se mostraram bastante eficazes", mas que nem sempre funcionaram: "Os fechamentos das pesquisas por email, algumas vezes foram complicados, pela disponibilidade de horário e até de participação de alguns membros do grupo" (A14). Tentou-se contornar este problema, proporcionando-lhes um tempo para o fechamento do problema no grupo no começo da aula, que foi sugerido pelos próprios alunos nas avaliações do processo e aprovado na avaliação final: “Os fechamentos em aula [...] foram muito mais válidos e proveitosos” (A14).

Parte importante do trabalho em grupo foi a delegação e alternância de papéis, que foram pensados tanto para contrabalançar o aumento da carga de trabalho individual dos alunos quanto para promover a troca de informações e a aprendizagem de habilidades distintas. As avaliações de grande parte dos alunos demonstram que isso pode ter sido alcançado: "O fato de assumir vários papéis contribuiu muito para um entendimento melhor do que é trabalho em equipe” (A05); "Os papéis estabelecidos foram muito bons, para que cada um não assumisse somente aquele papel que mais se identifica” (A14) e "A proposta de rodízio de papéis desenvolve no aluno habilidades de apresentação, escrita e liderança" (A16). Entretanto, há evidências de que nem sempre aconteceu o esperado, como relata A21: “Os papéis não foram definidos totalmente: muitas vezes todos 
agiam como líderes, todos auxiliavam na redação do relatório, e essa participação 'fora dos papéis' foi muito interessante”, A10: "Cada um soube assumir sua função, a não ser pelo líder, pois ninguém cobrava muito" e A15: "Os [papéis] mais definidos foram o redator e o porta-voz. O líder e os [demais] participantes tiravam 'folga' na semana (sem generalizar, o.k.?)”. Essas falas também sugerem a questão das atitudes (já discutida anteriormente), a participação desigual dos membros do grupo. Esses fatores são também relatados por Woods (2001) para grupos sem tutores individuais como os deste estudo, ou seja, somente com a supervisão do docente. Nestes casos seria mais difícil a delegação de responsabilidade e a responsabilização dos alunos perante seus colegas e o professor. Este autor acredita que alocar um tutor (tal como. um aluno de anos anteriores) para cada grupo, além do docente responsável pela disciplina, ou ainda, no caso de não se poder contar com tutores individuais, fazer com que as contribuições dos alunos sejam visíveis, por exemplo, através de diários individuais semanais documentando sua participação nas atividades, promoveriam um melhor acompanhamento do trabalho individual dentro dos grupos (WOODS, 1996).

Nesta implementação, um dos procedimentos adotados pelo docente para contornar estas dificuldades foi a redistribuição dos alunos em novos grupos (equipes) a partir do meio do semestre. Os grupos foram rearranjados para revitalizar o trabalho em grupo e evitar que os alunos se acomodassem em papéis de sua preferência. Alguns alunos perceberam esta mudança como positiva: "No segundo grupo ocorreu uma maior clareza das tarefas e o trabalho em equipe foi mais dinâmico e eficaz” (A13) e “A troca de grupo no meio do processo foi muito interessante, pois é como se trocássemos de ambiente de trabalho dentro da nossa empresa e experimentássemos tudo o que a mudança envolve" (A14).

Com relação às formas de apresentação dos resultados do trabalho dos grupos - ou seja, o diagnóstico dos problemas, as soluções e suas fundamentações teóricas - as diferentes formas utilizadas (relatórios, seminários, painéis e dramatizações) "mostraram-se adequadas e eficazes” (A06). O artifício de variá-las a partir do meio do semestre foi bem recebido, pois o uso repetido de seminários nos primeiros problemas foi desmotivante para alguns alunos, como relata A09: "No começo, lá pela $3^{\mathrm{a}}$ aula, quando percebi o esquema repetitivo da apresentação dos resultados, me senti desanimado e que estava preso a isso até o fim do semestre, mas depois isso mudou e foi muito impactante porque todos, e não apenas o redator, tiveram que concluir as idéias e seu formato de apresentação”. Esta fala de A09 levanta ainda o aspecto de alguns alunos ficarem desmotivados depois de passada a fase inicial da metodologia. Apesar de ser importante trazer uma gama variada de opções para uma determinada atividade de modo a desenvolver habilidades diferentes, é necessário verificar se esta desmotivação não é decorrente de um entendimento equivocado por parte dos alunos. Alguns alunos vêem a PBL apenas como infotainment (informação + entretenimento) (SAVIN-BADEN, 2000) e podem se ressentir, passada a fase da novidade, do trabalho que ela requer. É necessário mostrar aos alunos desde o princípio e relembrá-los ao longo da disciplina que, embora a aula sob esta metodologia seja mais dinâmica, ou mesmo mais divertida, seu objetivo é a construção de conhecimentos e o desenvolvimento de habilidades e atitudes e isto demanda esforço e tempo.

Assim, o propósito das apresentações, particularmente com turmas grandes, segundo Rangachari (1996), seria o de estimular os alunos a exercitarem suas habilidades comunicativas e ensinálos a comunicar de forma eficaz os conhecimentos que construíram - o que pode ser atestado pela fala de A04: "Proporcionaram o desenvolvimento de capacidades que alguns pensavam, até então, não serem capazes ou então nunca desenvolverem” - e o de prover mecanismos para que expressem suas idéias individualmente, o que se deu durante os debates subsequentes, no fechamento coletivo.

A fase do fechamento coletivo foi considerada importante por todos os alunos, como mostram A05: “Se constituía no ‘clímax’ de todo o processo” e A12: 
"O fechamento coletivo foi o mais proveitoso de todo o processo onde pudemos discutir várias visões para um mesmo problema”. A síntese do professor nesta fase foi valorizada: "O fechamento coletivo foi importante pois validava o conhecimento obtido e exposto pelos grupos" (A04); "É importante pelos comentários do professor” (A21). Em implementações da PBL como a relatada neste estudo, em que o docente atua como facilitador de vários grupos de alunos inexperientes na metodologia, énatural que o papel do professor se afaste um pouco daquele descrito por Barrows (2001): ele intervém em determinados momentos do processo de modo a garantir que os alunos sejam capazes de distinguir conceitos importantes de fatos triviais. Porém isso deve ser feito de modo que não prejudique sua transição da aprendizagem passiva para a ativa (ALLEN; DUCH; GROH, 1996). É preciso também observar se estas falas não estão refletindo as vivências destes alunos em metodologias pautadas na figura do professor como o detentor do conhecimento, ao qual, e somente a ele, cabe a palavra final que irá avalizar ou não as pesquisas feitas pelos alunos.

A última fase da aula era a avaliação, que consistia de dois momentos: a avaliação do processo (problema, dinâmica da aula etc. feita pelo grupo) e a avaliação do desempenho dos alunos (onde o líder, separadamente, avaliava a si mesmo e os demais membros do grupo). De modo geral, os alunos encontraram dificuldades nessa fase: "Achei interessante, mas às vezes ficava muito difícil avaliar através de notas [conceitos] por ser algo muito subjetivo" (A21). Como sugere Groh (2001), uma maneira de se evitar a dificuldade devido à subjetividade dos conceitos e o preenchimento pro forma das avaliações seria diminuir sua freqüência e oferecer feedback imediato aos alunos através de comentários construtivos anônimos dos colegas.

Apesar de a avaliação ter sido considerada boa e "de extrema importância para que os alunos demonstrassem seus pontos de vista sobre a aula" (A20), ela foi tomada separadamente e notou-se, que o aproveitamento foi aquém do esperado. Isso se deve tanto a maneira como fizeram esta avaliação durante o semestre, de forma mecânica, quanto a forma como responderam sobre este ponto no questionário final (isto é, confundindo a avaliação do processo com a avaliação de desempenho ou dando uma resposta conjunta para as duas). Existe, pois, a necessidade de melhoria deste instrumento, principalmente por acreditar-se que seja importante para o desenvolvimento de uma atitude reflexiva sobre o processo de ensino-aprendizagem. Já a avaliação de desempenho foi melhor aproveitada, como indica A01: "Foi de grande valia. Levou a equipe a repensar o seu envolvimento com as tarefas que foram designadas, individualmente”. Contudo, há evidências de que este procedimento também foi prejudicado por atitudes e estratégias de sobrevivência adquiridas durante a escolarização dos alunos: "A idéia de que a avaliação de desempenho poderia afetar a nota final de algum componente do grupo fez com que não fosse tão crítico e realista como devia. Com o passar das semanas houve uma melhor consciência da importância da avaliação ser mais real para ajudar o processo" (A12). Para minimizar este efeito, percebido durante o semestre através das avaliações e relatos informais dos alunos, tentou-se mostrar-lhes a importância deste procedimento e a responsabilidade nele embutida, além da possibilidade de estarem vivenciando situações passíveis de serem encontradas em um ambiente profissional real, o que foi reconhecido por A04: "Mostrou a importância em sua auto-avaliação e na avaliação de seus colegas, tentando isolar o relacionamento pessoal (uma atitude que os administradores e gerentes precisam ter)”.

\section{Considerações Finais}

Apesar de ser um estudo com resultados parciais, haja vista que a avaliação do professor e questões institucionais também devam ser levadas em conta, em geral as falas dos alunos apontam para a viabilidade do uso do método de ensino no contexto estudado, desde que alguns aspectos do mesmo, tais como número de problemas apresentados, sejam repensados e redimensionados. 
Embora tenham ocorrido alguns problemas na implementação, detectados pelas atividades inerentes à PBL (avaliações processuais dos alunos) e pela observação do próprio professor e corrigidos no decorrer do semestre, os objetivos da disciplina foram satisfatoriamente alcançados. O método parece ter sido eficaz em oferecer aos alunos uma visão global sobre o pensamento administrativo e oportunidades de discussão sobre as teorias adjacentes, além de proporcionar o exercício e desenvolvimento de algumas habilidades e atitudes consideradas importantes para os estudantes de pós-graduação em engenharia de produção.

A implementação também parece ter sido capaz de sensibilizar a maioria dos estudantes, possíveis futuros professores, para a existência de métodos de instrução alternativos à sala de aula convencional. Mesmo mostrando certa resistência, alguns alunos que já atuavam como docentes afirmaram ter apreciado a PBL e que estavam pensando em utilizar o método em suas próprias aulas ou em partes delas.

Contudo, é importante deixar claro que a formação de pesquisadores e docentes em quaisquer campos de conhecimento é reconhecidamente um processo complexo, portanto, não se deseja simplificá-la ou considerar a experiência aqui relatada suficiente para esta finalidade. Ao contrário, este trabalho têm a intenção de mostrar caminhos alternativos para a prática pedagógica universitária, tentando contribuir com outros enfoques para o aprimoramento do ensino de pós-graduação e do ensino superior de modo geral, na área de engenharia ou outra.

\section{Referências}

ALBANESE. M. A.; MITCHELL, S. Problem-based Learning: a review of literature on its outcomes and implementation issues. Academic Medicine, Washington, v.68, n.1, p.52-81, 1993.

ALLEN, D. E.; DUCH, B. J.; GROH, S. E. The power of Problem-based Learning in teaching introductory science courses. In: WILKERSON, L.; GIJSELAERS, W.H. (Ed.). Bringing Problem-based Learning to higher education. San Francisco: Jossey-Bass Publishers, 1996. p.43-52.

BARROWS, H. S. Problem-based Learning in medicine and beyond: a brief overview. In: WILKERSON, L.;
GIJSELAERS, W. H. (Ed.). Bringing Problem-based Learning to higher education. San Francisco: JosseyBass Publishers, 1996. p.3-12.

BARROWS, H. Problem-based Learning (PBL). Disponível em: <http://www.pbli.org/pbl>. Acesso em: 16 jun. 2001.

BRASIL. Ministério da Educação e Cultrua. Diretrizes curriculares nacionais para os cursos de engenharia. Disponível em: <http://www.mec.gov.br>. Acesso em: 19 out. 2002.

COLE, A. L.; KNOWLES, J. G. Teacher development partnership research: a focus on methods and issues. American Educational Research Journal, Washington, v.30, n.3, p.473-495, 1993.

CUNHA, M. I. A aula universitária: inovação e pesquisa. In: ENCONTRO NACIONAL DE DIDÁTICA E PRÁTICA DE ENSINO, 8., 1996, Florianópolis. Anais...Florianópolis: UFSC, 1996. 1996. v.2, p.354-362.

DENZIN, N.K.; LINCOLN, Y.S. Handbook of qualitative research. Thousand Oaks, CA: Sage Publications, 1994.

Denzin Norman K., Lincoln Yvonna S. (eds.), Handbook of Qualitative Research, Thousand Oaks 1994

DOCHY F.; SEGERS, M.; VAN DEN BOSSCHE, P.; GIJBELS, D. Effects of Problem-based Learning: a metaanalysis. Learning and Instruction, Oxford, v.3, p.533568, 2003.

DUCH, B. What is problem-based learning? Disponível em : <http://www.udel.edu/pbl/cte/jan95-what.html>. Acesso em: 26 abr. 2000.

FOGARTY, R. (Ed.). Problem-based Learning: a collection of articles. Arlington Heights: Skylight, 1998.

GIJSELAERS, W. H. Connecting problem-based practices with educational theory. In: WILKERSON, L.; GIJSELAERS, W. H. (Ed.). Bringing Problem-based Learning to higher education. San Francisco: JosseyBass Publishers, 1996. p.13-21.

GROH, S. E. Using Problem-based Learning in general chemistry. In: DUCH, B. J.; GROH, S. E.; ALLEN, D. E. (Ed.). The power of problem-based learning. Sterling: Stylus, 2001. p.207-218.

KAUFMAN, D. M.; MANN, K. V. I don't want to be a groupie. In: SCHWARTZ, P.; MENNIN, S.; WEBB, G. (Ed.). Problem-based Learning: case studies, experience and practice. Londres: Kogan Page, 2001. p.142-150.

KINGSLAND, A. J. Time expenditure, workload, and student satisfaction in Problem-based Learning. In: WILKERSON, L.; GIJSELAERS, W.H. (Ed.). Bringing Problem-based Learning to higher education. San Francisco: Jossey-Bass Publishers, 1996. p.73-81. 
RANGACHARI, P. K. Twenty-up: Problem-based Learning with a large group. In: WILKERSON, L.; GIJSELAERS, W.H. (Ed.). Bringing Problem-based Learning to higher education. San Francisco: Jossey-Bass Publishers, 1996. p.63-72.

SAVIN-BADEN, M. Problem-based Learning in higher education: untold stories. Buckingham: Open University Press, 2000.

STEPIEN, W. J.; GALLAGHER, S. A. Problem-based Learning: as authentic as it gets. In: FOGARTY, R. (Ed.). Problem-based Learning: a collection of articles. Arlington Heights: Skylight, 1998. p.43-50.

STINSON, J. E.; MILTER, R. G. Problem-based Learning in business education: curriculum design and implementation. In: WILKERSON, L.; GIJSELAERS, W.H. (Ed.). Bringing Problem-based Learning to higher education. San Francisco: Jossey-Bass Publishers, 1996. p.33-42.
WILKERSON, L.; GIJSELAERS, W. H. Bringing Problembased Learning to higher education. San Francisco: Jossey-Bass Publishers, 1996. p.23-32

WOODS, D. Problem-based Learning for large classes in chemical engineering. In: WILKERSON, L.; GIJSELAERS, W. (Ed.). Bringing Problem-based Learning to higher education. San Francisco: Jossey-Bass Publishers, 1996. p.91-99.

WOODS, D. Problem-based Learning, especially in the context of large classes. MacMaster University, Department of Chemical Engineering Web Site. Disponível em: <http://chemeng.macmaster.ca/pbl/pbl.htm>. Acesso em: 31 ago. 2000.

WOODS, D. They just don't pull their weight. In: SCHWARTZ, P.; MENNIN, S.; WEBB, G. (Ed.). Problembased Learning: case studies, experience and practice. Londres: Kogan Page, 2001. p.163-170.

ZABALA, A. A prática educativa: como ensinar. Porto Alegre: Artmed, 1998. p.195-221. 
